\title{
(j)
}

\author{
AL-DZIKRA \\ Jurnal Studi Ilmu Al-Qur'an Dan Al-Hadits \\ http://ejournal.radenintan.ac.id/index.php/al-dzikra \\ Volume 14, No. 1, Juni Tahun 2020, Halaman 79 - 98 \\ DOI://dx.doi.org/10.24042/al-dzikra.v14i1.6314
}

\section{Varietas Azab Di Dunia Dalam Al-Qur'an (Penafsiran Tematik QS. Al-Ankabut: 40)}

\begin{tabular}{c}
\hline Yoga Riyandi \\
UIN Raden Intan Lampung \\
zainqaisalhaq@gmail.com \\
\hline
\end{tabular}

\section{Abstract}

The Qur'an not only serves as a guidance for Muslims but also admonition for humans. Through its revelation, God gives rewards to those who obey Him and threatens with punishments to those who disobey Him. Q. al-Ankabut: 40one of Qur'anic verses discussing torment. The type of torment according to the Qur'an is divided into two: torment in the world and torment in the afterlife. The former can be understood in terms of both formal and substantial torment. Understanding the torment in the world, therefore, can encourage Muslims to avoid disobedience to God. Performing God's commands is the very principle of human creation. Indeed, torment according to the Qur'an is not limited to four categories. But, this article particularly discusses four categories of torment in the world explained in $Q$. alAnkabut: 40, namely Hasiba, Ash Shaihah, Khasafa fil Ardhi, and Aghraqa. These four torments are related to God's speech in the previous verses and other verses in the Qur'an. It is significant, therefore, to study the verse to understand God's torments to humans. The verse should be read thematically in relation to other verses. 


\section{Abstrak}

Al-Qur'an di samping sebagai hukum pedoman bagi umat Islam berfungsi juga sebagai sebuah kitab peringatan untuk manusia. Di dalamnya Allah swt. memberikan janji bagi orang-orang yang taat kepada-Nya dan mengancam dengan azab bagi yang durhaka kepada-Nya. QS. Al-Ankabut: 40 merupakan salah satu contoh ayat yang membicarakan tentang azab dari sekian banyak ayat. Karena pembahasan azab dalam al-Qur'an secara prinsipnya terbagi menjadi dua; yaitu azab di dunia dan azab di akhirat. Azab di dunia terbagi pula kepada azab yang dhahir dan maknawi. Mengetahui azab yang Allah swt. turunkan di dunia mampu mempengaruhi seseorang untuk menjauhi kemaksiatan kepada-Nya. Dan menjauhi azab dengan mewujudkan perintah Allah swt. merupakan perkara asas penciptaan manusia. Azab dalam al-Qur'an tidak terbatas pada 4 jenis saja, akan tetapi pada pembahasan ini dibatasi pada kajian surah Al-Ankabut ayat 40 yang mengkaji 4 jenis azab di dunia. Yaitu Hasiba, Ash Shaihah, Khasafa fi Al Ardhi dan Aghraqa. Keempat azab tersebut memiliki keterkaitan dengan pembicaraan Allah swt. pada ayat-ayat sebelumnya dan ayat-ayat pada surat yang lain. Oleh karenanya sangat perlu mengkaji ayat tersebut agar mendapatkan kesimpulan yang benar terkait azab yang Allah berikan kepada hambanya. Kemudian akan disandingkan dengan beberapa ayat dan penafsiran yang berkaitan dengan tema azab.

Kata Kunci: Azab Dunia, Empat Azab, Azab Dhahir.

\section{A. Pendahuluan}

Al-Qur'an didefinisikan oleh para ulama sebagai kitab Allah swt. yang diturunkan kepada nabi Muhammad dan membacanya merupakan sebuah bentuk ibadah. ${ }^{1}$ Turunnya memiliki fungsi sebagai petunjuk dan penjelas bagi manusia agar selalu lurus di atas konsekuensi perjanjian ilahi sebelum dilahirkan ke bumi. Perjanjian itu diabadikan Allah swt. dalam surah al-A'raf ayat 172

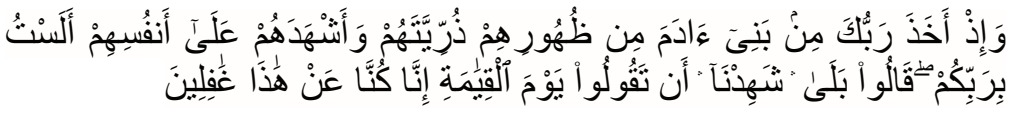

"Dan (ingatlah), ketika Rabmu mengeluarkan keturunan anak-anak Adam dari sulbi mereka dan Allah mengambil kesaksian terhadap

${ }^{1}$ Manna' Khalil Al-Qaththan, "Mâbahits fì Ùlûm Al-Qur'an" (Kairo: Maktabah Wahbah, t.t.), hlm. 15. 
jiwa mereka (seraya berfirman): "Bukankah Aku ini Rabmu?" Mereka menjawab: "Betul (Engkau Rab kami), kami menjadi saksi". (Kami lakukan yang demikian itu) agar di hari kiamat kamu tidak mengatakan: "Sesungguhnya kami (bani Adam) adalah orangorang yang lengah terhadap ini (keesaan Allah)".

Konsep petunjuk dalam al-Qur'an adalah memberikan arahan-arahan kepada ketentuan Allah swt. dengan aplikasi syari'at yang telah diperintahkan di dalam al-Qur'an. Dari maksud ini retorika al-Qur'an terkadang bernada janji kebaikan dan terkadang bernada ancaman. Ada berberapa tahapan petunjuk dalam al-Qur'an, pertama: petunjuk yang umum, yaitu petunjuk Allah swt. untuk seluruh makhlukNya kepada hal yang mendatangkan kebaikan. Sehingga didapati berbagai jenis hewan memakan makanan yang berbeda sesuai kebutuhan untuk mendapatkan kemaslahatannya. Dalam surah al-A'la ayat 3 Allah swt. jelaskan bahwa Dia telah menciptakan dan memberikan petunjuk, Ibnu Katsir menjelaskan bahwa petunjuk kepada manusia untuk mendapatkan kebahagiaan dan petunjuk kepada binatang kepada makanannya. ${ }^{2}$ Kedua: petunjuk untuk memberikan bukti dan penjelasan serta pembelajaran, petunjuk ini merupakan kekhususan bagi para rasul dan kitab-kitab yang diturunkan dari langit. Seperti yang telah ditetapkan kepada Rasulullah dalam surah asy-Syura ayat 52; dalam ayat tersebut Allah swt. tegaskan kepada Rasulullah bahwa beliau benar-benar akan menjadi petunjuk kepada jalan yang lurus; yaitu agama Islam. $^{3}$ Ketiga: petunjuk dari Allah swt. dan pertolongannya, tingkatan ini lebih khusus dari sebelumnya, karena ini adalah petunjuk khusus yang datang setelah penjelasan. Namun tidak semua yang mendapatkan penjelasan mendapatkan petunjuk ini, karena ini merupakan karunia yang Allah swt. berikan kepada hamba-hamba yang dikehendakiNya. Seperti firman Allah swt. dalam surah al-Qashash ayat 56, bahwa nabi Muhammad tidak bisa memberikan petunjuk kepada yang beliau cintai, melainkan Allah swt. yang memberikan petunjuk kepada yang Dia kehendaki.

${ }^{2}$ Ismail Ibn Katsir, "Tafsîr Al-Qur'ân Al-`Adzîm", Jilid. VIII (Kairo: Al Maktabah At Tufiqiyyah, 2012), hlm. 247.

${ }^{3}$ Sekumpulan Ulama' Tafsir, “Al-Mukhtashar fî Tafsîr Al-Qur'ân AlKarîm" (Riyad: Markaz Tafsir liddirasat At Tafsiriyyah, 1439), hlm. 489. 
Keempat: petunjuk menuju surga dan neraka di hari kiamat, inilah akhir tingkatan petunjuk. Bagi orang-orang yang mendapatkan petunjuk dari Allah swt. serta mengamalkan petunjuk tersebut di dunia maka mereka akan mendapatkan jalan kemudahan menuju surga. Akan tetapi sebaliknya, jika orang-orang yang mendapatkan petunjuk dan tidak mengamalkannya maka akan ditunjukkan jalan ke neraka.

Dalam konteks azab yang telah diuraikan dalam al-Qur'an masih banyak yang belum ditangkap oleh mayoritas kaum muslimin. Pasalnya anggapan azab neraka merupakan satu-satunya balasan Allah swt. kepada orang-orang yang durhaka dan berbuat dzalim adalah pemahaman yang final. Sehingga dari anggapan ini akan memunculkan sikap aman selagi masih di dunia, dan fungsi utama al-Qur'an akan semakin pudar. Dalam konsepnya Allah swt. tidak hanya memberikan azab ketika keberadaan manusia telah terlepas dari alam dunia, melainkan terdapat azab-azab yang Allah swt. segerakan di dunia untuk orang-orang yang durhaka kepadaNya. Keberagaman azab tersebut mengikuti keberagaman kehidupan manusia yang heterogen.

Upaya eksploitasi al-Qur'an untuk memahami dan mentadabburi isi kandungannya agar mendatangkan nilai-nilai keutuhan manusia adalah menggunakan metode tafsir. Adapun metode dalam menafsirkan al-Qur'an sangatlah beragam, keberagaman tersebut sesuai dengan macam bentuk tafsir yang ada ${ }^{4}$ di antara macamnya adalah penafsiran dengan metode maudhî̂ atau tematik menjadi pilihan peneliti, yaitu ilmu yang membahas sebuah masalah sesuai dengan maksud al-Qur'an dari kandungan ayat atau surah. Sebagian ulama ada yang membagi atTafsîr al-Maudhûî kepada dua sisi pembahasan, antara keduanya memiliki keterkaitan dari beberapa sisi. Pertama, mengumpulkan sebuah kesamaan dan korelasi dalam al-Qur'an sesuai dengan pembahasan kata linguistik, kemudian menyusunnya sesuai dengan susunan mu'jam. Kedua, memaparkan suatu pembahasan kemudian mengumpulkan ayat-ayat yang terpisah di beberapa

${ }^{4}$ Di antara macam bentuk tafsir adalah: At Tafsî́r bi Al Ma'tsĥ́r, At Tafsî́r bi Aŕ Ŕa 'ŷ̀ atau Al Aqlî, At Tafsîr Al Maudhû̂, At Tafsî́r Al Isyârî dan At Tafsî̀ Al Ìlmî. Lihat: Muhammad Husain Adz-Dzahabi, "Ìlmu At-Tafsîr" (Kairo: Dar Al-Maárif, t.t.), hlm. 39. 
surah dalam al-Qur'an yang memiliki korelasi dengannya, baik ayat-ayat yang memiliki kesamaan dalam lafal ataupun makna serta keterkaitan kuat dengan tema pembahasan walaupun hanya sebagian sisinya saja. ${ }^{5}$

Penafsiran tematik memiliki peran yang sangat penting dalam penelitian al-Qur'an, karena pada penafsiran ini tidak terbatas pada tema-tema tertentu melainkan pembahasannya akan selalu baru dan berkembang sesuai situasi dan kondisi yang ada. Melihat perkembangan kehidupan manusia dalam segala aspek memungkinkan bagi penafsiran tematik untuk merasuk menyelaminya, hal ini membuktikan bahwa al-Qur'an adalah kitab yang shâlihun li kulli makân wa zamân.

Terdapat kajian mengenai azab yang ditulis Abdul Rahman Rusli Tanjung dalam jurnal Analytica Islamica yang berjudul "Korelasi perbuatan dosa dengan azab yang diturunkan Allah dalam prespektif Al-Qur'an". Di dalamnya dibahas lafal-lafal dalam al-Qur'an yang menunjukkan makna dosa dan korelasi antara pelanggaran terhadap kebebasan dan hak-hak asasi manusia dengan azab yang bersifat kolektif.

Dalam penelitian ini, dibahas satu tema yang terkandung dalam surah al-Ankabut ayat 40 terkait varietas azab Allah swt. yang diturunkan kepada hamba-Nya. Dalam ayat tersebut terdapat empat azab yang disegerakan Allah swt. di dunia untuk orangorang yang menentang dakwah para nabi yang diutus kepada mereka. Keempat azab tersebut akan dianalisa latar belakang dan reaksi yang muncul darinya. Sehingga dapat dipetakan korelasi sebab dan akibat yang muncul. Penelitian ini menempuh metode tematik, yaitu ${ }^{6}$ satu ayat di surah al-Ankabut: 40 yang akan disandingkan dengan metode tematik dari berbagai macam ayat, karena kandungan dalam ayat tersebut memiliki keterkaitan kisah dan peristiwa dengan surah dan ayat yang lain. Kemudian dalam pembahasan ini, terdapat kaidah penunjang guna untuk lebih banyak menemukan temuan dalam tema penafsiran dari ayat

5 Abbas Audhullah Abbas, "Muhâdharât fî At-Tafsîr Al-Maudhûî" (Damaskus: Dar Al-Fikr, 2007), hlm. 19-20.

${ }^{6}$ Musthafa Muslim, "Mabâhits fî̀ At-Tafsîr Al-Maudhû̀̂" (Riyad: Dar At-Tadmuriyyah, 2009), hlm. 38-39. 
tersebut. Seperti kaidah munasabah, kaidah kisah dalam al-Qur'an dan sebagainya.

\section{B. Deskripsi Surah Al-Ankabut: 40}

Surah al-Ankabut adalah surah ke-29 dalam al-Qur'an, surat ini terdiri dari 69 ayat, dinamai al-Ankabut karena dalam ayat 41 pada surat tersebut terdapat kata al-Ankabut yang berarti labalaba.

Redaksi QS. al-Ankabut: 40;

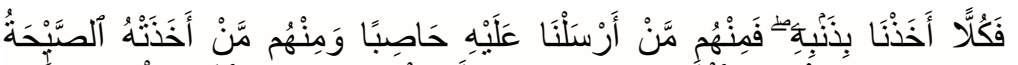

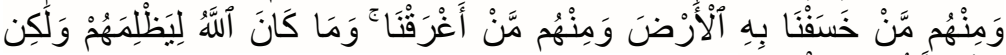

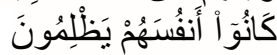

"Maka masing-masing Kami siksa disebabkan dosanya, maka dari mereka ada yang Kami timpakan kepadanya hujan batu kerikil dan di antara mereka ada yang ditimpa suara keras yang mengguntur, dan di antara mereka ada yang Kami benamkan ke dalam bumi, dan di antara mereka ada yang Kami tenggelamkan, dan Allah sekalikali tidak ingin mendzalimi mereka, melainkan merekalah yang mendzalimi diri mereka sendiri”.

Ayat 40 ini adalah ayat dari surah makkiyah ${ }^{7}$ yaitu sebagai salah satu ayah dari surat yang Allah swt. turunkan sebelum Rasulullah hijrah ke Madinah. Karena penentuan Makki dan Madani menurut sebagian Ulama' terletak pada sisi historis bukan geografis. Perincian dari kedua pembagian ini merupakan penentuan yang selamat, karena ada sebagian ayat yang terkategorikan madaniyyah namun secara geografis turun di Makkah. Seperti ayat 3 dalam surah al-Maidah yang Allah swt. turunkan pada hari Jumát di Arafah pada peristiwa haji Wada', walaupun secara geografis turun di Arafah daerah sekitar Makkah namun secara historis turun setelah Rasulullah hijrah ke Madinah. ${ }^{8}$

QS. Al-Ankabut: 40 didahului dengan kalimat فَكُلَّ, kalimat tersebut dibaca manshub karena menduduki posisi objek dari kata

${ }^{7}$ Muhammad Salim Muhaisin, "Târîkh Al-Qur'ân Al-Karîm" (Jeddah: Dar Al-Ashfahan, 1402), hlm. 52.

${ }^{8}$ Muhammad Abdul Adzim Az-Zarqani, "Manâhil Al-İrfân fì Ùlûm AlQur'ân", Jilid. 1 (Lebanon: Dar Al-Kutub Al-Arabi, 1995), hlm. 160-161. 
أَخَذْنَا. 9 Secara kaidah asal dalam ilmu nahwu bahwa objek datang setelah predikat dan subjek, ${ }^{10}$ Ibnu Malik mengatakan:

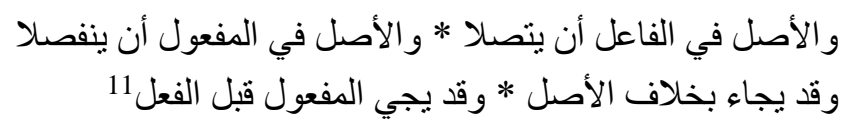

"Asal penyebutan fa'il/subjek harus bersambung, dan asal penyebutan mafül/objek harus berpisah

Terkadang juga didatangkan dengan hukum yang menyalahi asal, dan terkadang mafùl/objek datang sebelum fiill/predikatnya".

Namun ketika objek disebut sebelum subjek dan predikat, maka memiliki beberapa makna, salah satunya adalah perhatian terhadap suatu perkara pada konteks kalimat tersebut. ${ }^{12}$ Dalam ayat ini, perhatian tertuju pada kesesuaian azab yang Allah swt. turunkan pada heterogenitas sosial budaya. ${ }^{13}$

Ayat ini datang setelah Allah swt. menceritakan kisahkisah umat terdahulu yang melakukan kemaksiatan dalam berbagai macam corak. Dari kemaksiatan-kemaksiatan tersebut kemudian Allah swt. menyampaikan terkait hukuman yang Allah swt. berikan kepada mereka sebagai bentuk keadilan yang ada pada Allah swt. Oleh karenanya di akhir ayat ini Allah swt. tutup dengan kalimat;

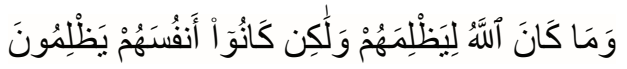

"Dan Allah sekali-kali tidak ingin mendzalimi mereka, melainkan merekalah yang mendzalimi diri mereka sendiri”.

\section{Tafsir QS. Al-Ankabut 40}

Pembicaraan pada ayat ini terkait orang-orang kafir dan yang mendustakan para rasul, di ayat sebelumnya Allah

9 Ahmad bin Muhammad bin Ismail An-Nahas, "I'râb Al-Qurân", Jilid. III (Maktabah Nahdzah Al-Arabiyyah, 1985), hlm. 256.

${ }^{10}$ Husna Abdul Jalil Yusuf, "Tashîl Syarh Ibn Àqûl" (Kairo: Yayasan Al-Mukhtar, 2000), hlm. 197.

${ }^{11}$ Bahauddin Abdullah bin Aqil, "Syarh Ibn Àqûl", Jilid. II (Kairo: Dar Ath-Thalaì, 2004), hlm. 43.

12 Ibnu Aqilah Al-Makki, "Az-Ziyâdah wa Al-Ihsân fì Ùlûm AlQur'ân", Jilid. VI (UEA: Markaz Al-Buhuts wa Ad-Dirasah, 2006), hlm. 11.

${ }^{13}$ Ibn Katsir, "Tafsîr Al-Qur'ân Al-`Adzîm", hlm. 119. 
mengkisahkan kaum Ád, Tsamud, Madyan, kaum Luth, Qarun, Firáun, Haman. Maka kalimat yang tepat untuk mengungkapkan mereka semua adalah kata فَكَكََّّ, karena mereka hakikatnya golongan yang sama. Harakat tanwin pada huruf lammerupakan ganti dari seluruh yang telah disebutkan sebelumnya.

Ayat ini datang setelah Allah swt. jelaskan kedurhakaan umat-umat terdahulu sebelum datangnya Rasulullah, maka huruf

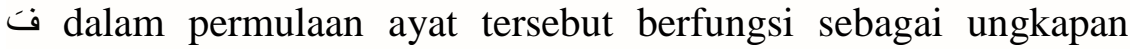
pemisah dari pembicaraan sebelumnya yang menggambarkan upaya setan dalam memberikan angan-angan indah di setiap perbuatan kedurhakaan mereka. ${ }^{14}$ Kemudian Allah swt. menyebutkan jenis-jenis azab yang disegerakan di dunia, azab tersebut ialah:

> Hujan batu kerikil dari langit yang ditimpakan kepada kaum nabi Luth, ${ }^{15}$ dan ada juga yang berpendapat kaum 'Àd. ${ }^{16}$ Dalam ayat tersebut menggunakan ungkapan حَاصِبًا, yaitu angin atau awan yang berhembus bercampur dengan benda lain, dan dalam hembusannya menimbulkan rasa sakit karena benda yang terbang bersamanya. ${ }^{17}$

$>$ Suara keras yang mengguntur. Ath-Thabari memaparkan perbedaan pendapat para mufassir terkait kepada siapakah azab ini ditimpakan. Kemudian cenderung kepada pendapat yang menyatakan bahwa azab tersebut turun kepada Tsamud dan kaum nabi Syuáib dari penduduk Madain. ${ }^{18}$

> Dibenamkan ke dalam bumi, yaitu azab yang Allah swt. timpakan kepada Qarun. ${ }^{19}$

14 Muhammad Ath Thahir Ibnu Asyur, "Tafsîr At-Tahrîr wa AtTanwîr", Jilid. XX (Tunisia: Ad-Dar At-Tunisiyyah, 1984), hlm. 251.

15 Sekumpulan Ulama' Pilhan, "At-Tafsîr Al-Muyassar" (Mesir: Dar Al-Islam, 2012), hlm. 401.

${ }^{16}$ Ibn Katsir, "Tafsîr Al-Qur'ân Al-`Adzîm", hlm. 119.

17 Ibnu Athiyyah Al Andalusi, "Al-Muharrar Al-Wajîz fî Tafsîr AlKitâb Al-Azîz", Jilid. IV (Lebanon: Dar Al-Kutub Al-Ilmiyyah, 2001), hlm. 317.

${ }^{18}$ Muhammad Ibn Jarir Ath-Thabari, "Tafsîr Ath-Thabarî", Jilid. XVIII (Kairo: Markaz Al-Buhuts wa Ad-Dirasat Al-Arabiyyah wa Al-Islamiyyah, 2001), hlm. 401-402.

19 Jamaluddin Al-Baghdadi, "Zâd Al-Masîr fì Ilmi At-Tafsîr", Jilid. VI (Beirut: Al-Maktabah Al-Islamiyyah, 1984), hlm. 272. 
> Ditenggelamkan ke dalam air, yaitu azab kepada Firaun dan Haman beserta bala tentaranya. ${ }^{20}$ Begitu juga kaum nabi Nuh yang Allah swt. tenggelamkan dalam banjir bah. ${ }^{21}$

Dalam ayat ini, Allah swt. menyebutkan ada empat jenis azab yang disegerakan di dunia bagi orang-orang yang kufur dan mendustakan-Nya. Di dalamnya terdapat bukti bahwa Allah swt. tidak mengazab seorang kecuali atas dasar dosanya. Karena azab tanpa didahului dengan kedurhakaan bukan merupakan sunnah Allah swt., dan tidak mengikuti manhaj hikmah yang keluar dari kebijakan al-Hakim. $^{22}$

Wahab bin Munabbih menuturkan:

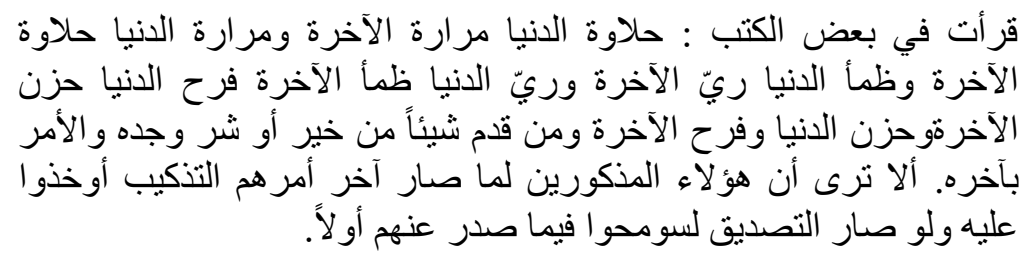

"Aku telah membaca di sebagian buku-buku: nikmat di dunia sengsara di akhirat dan sengsara di dunia nikmat di akhirat, haus di dunia puas di akhirat dan puas di dunia haus di akhirat, senang di dunia sedih di akhirat dan sedih di dunia senang di akhirat. Siapa yang mendahulukan kebaikan atau keburukan maka dia akan mendapatkannya, dan perkaranya terletak pada akhirnya Tidakkah engkau melihat orang-orang yang telah disebutkan (dalam ayat), ketika akhir perkara mereka adalah mendustakan maka mereka akan di azab, seandainya mempercayai (Allah) merupakan akhir perkaranya, maka mereka akan dipersilahkan untuk mendapatkan awalnya". ${ }^{23}$

Terdapat keterangan mengenai objek azab pada ayat ini, dalam surat Qaf ayat 12-14 Allah swt. berfirman;

${ }^{20}$ Abdurrahman As-Sa'di, "Taisîr Al-Karîm Ar-Rahmân" (KSA: AlBayan, t.t.), hlm. 740 .

${ }^{21}$ Musthafa Al-Hishn Al-Manshuri, "Al-Muqtathaf min Ùyûn AtTafâsîr", Jilid. VI (Beirut: Ad-Dar Asy-Syamiyyah, t.t.), hlm. 179.

22 Muhammad Amin Asy-Syafií, "Tafsîr Hadâiq Ar-Rûh wa ArRahmân", Jilid. XXI (Lebanon: Dar Thuq An-Najah, 2001), hlm. 415.

${ }^{23}$ Ismail Musthafa Al-Hanafi, "Tafsîr Rûh Al-Bayân", Jilid. VI (Dar Ihya' At-Turats Al-Arabi, t.t.), hlm. 341. 


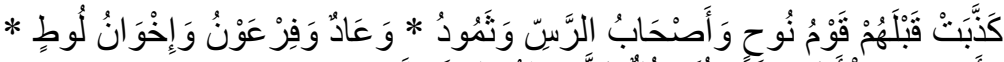

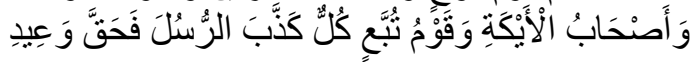

"Sebelum mereka ada yang telah mendustakan pula (yaitu) kaum nabi Nuh dan penduduk Rass dan Tsamud. Serta 'Àd, Firaun dan Saudara nabi Luth. Dan penduduk Aikah serta kaum Tubba', semuanya telah mendustakan rasul-rasul, maka sudah sepantasnya mereka mendapatkan azab yang telah diancamkan”.

\section{Kajian Tematik QS. Al-Ankabut: 40 Terkait Varietas Azab di Dunia.}

a. Kajian dalam tema lafal حَاصِبًا.

Sَ Sَاصِبًا berarti angin atau awan yang berhembus bercampur dengan benda lain. Sehingga dari makna lafal ini ada yang berpendapat bahwa azab tersebut turun kepada kaum nabi Luth dan kaum 'Àd. Namun terdapat penjelasan lain yang menspesifikkan lafal diberikan kepada kaum nabi Luth. Dalam surah al-Qamar ayat 34 Allah swt. berfirman;

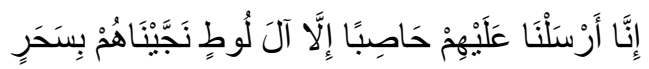

"Sesungguhnya kami telah mengirimkan angin yang melemparkan batu-batu kepada mereka, kecuali keluarga Luth.Kamitelah selamatkan mereka (keluarga Luth) sebelum terbit fajar".

Penuturan Ibnu Katsir terkait ayat ini;

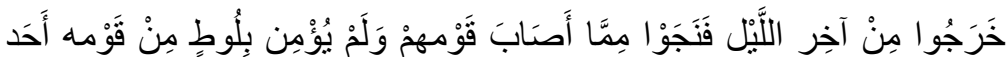

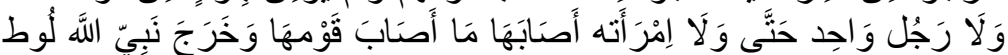

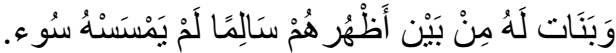

"Keluarga nabi Luth keluar di akhir malam, dan mereka selamat dari musibah yang menimpa kaumnya. Dari kaum nabi Luth tidak ada seorangpun yang beriman kepadanya bahkan istrinya mendapatkan apa yang didapatkan kaumnya. Sedangkan nabi Allah Luth dan putri-putrinya keluar dari tengah-tengah mereka selamat dari keburukan yang menimpa mereka". ${ }^{24}$

${ }^{24}$ Ibn Katsir, "Tafsîr Al-Qur'ân Al-`Adzîm", hlm. 311. 
Keterangan dari Ibnu Katsir ini dikuatkan dengan firman Allah swt. dalam QS. Al-A'raf ayat 83;

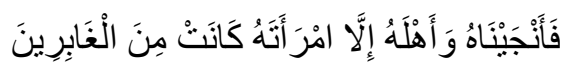

"Kemudian kami selamatkan dia (nabi Luth) dan pengikutnya, kecuali istrinya.Dia (istrinya) termasuk orang-orang yang tertinggal".

Terdapat tambahan penjelasan lafal حَاصِبً dalam tafsir alQurthubi, pada penafsiran surah al-Mulk ayat 17 dikatakan:

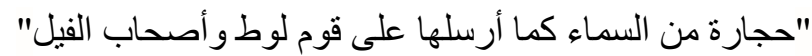

"Bebatuan dari langit sebagaimana yang telah ditimpakan atas kaum Luth dan pasukan gajah". ${ }^{25}$

Dari kedua tafsir di atas, maka lafal حَاصِبً adalah azab yang Allah swt. turunkan kepada orang-orang yang membangkang kepadaNya dalam bentuk angin yang kencang disertai lontaran bebatuan. Bukti dari kesimpulan ini adalah firman Allah swt. dalam QS. Hud: 82;

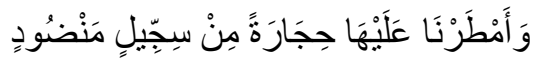

"Dan Kami hujani mereka dengan batu dari tanah yang terbakar dangan bertubi-tubi”. (QS. Hud: 82).

Terkait ayat di atas, al-Qurthubi menukil dari beberapa mufassir, dikatakan di dalamnya;

وقال قتادة وعكرمة: السجيل الطين بدليل قوله " لِنْرُسِيلَ عَلَيْهِْْ حِجَارَةً مِنْ

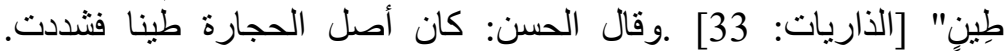
و السجِيل عند العرب كل شديد صلب.

"Dan telah berkata Qatadah dan Ikrimah: السجيل adalah tanah, dengan dalil firman Allah; "Sungguh telah dikirimkan kepada mereka batu dari tanah" [QS. Adz Dzariyat: 33]. Al Hasan berkata: Asal dari batu adalah tanah kemudian mengeras. Dan السجيل menurut orang Arab adalah setiap yang keras dan padat. ${ }^{26}$

25 Muhammad bin Ahmad bin Abu Bakar Al-Qurthubi, "Al-Jâmi Liahkâm Al-Qur'ân", Jilid. XXI (Lebanon: Yayasan Ar-Risalah, 2006), hlm. 127.

${ }^{26}$ Al-Qurthubi, hlm. 187. 
Dalam tafsir Taisî́r Al-Karî̀m Aŕ-Ŕahmân, Abdurrahman As-Sa'di menjelaskan kata سِجِِّ adalah batu neraka yang keras lagi panas, dan lafal مَنْضُوٍ adalah saling mengiringi, yaitu mengiringi siapa saja yang keluar dari negeri tersebut. ${ }^{27}$

Dari beberapa penafsiran di atas, terdapat korelasi antara angin dan saling mengiringi, yaitu bebatuan tersebut senantiasa mengejar mengiringi orang-orang yang keluar dari negeri itu dengan bantuan hembusan angin.

Ath-Thabari menambahkan penjelasan terkait radius dari azab yang ditimpakan kepada kaum nabi Luth, dalam tafsirnya beliau mengatakan;

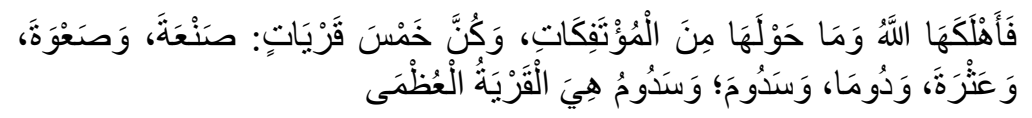

"Maka Allah binasakan mereka dan sekitar mereka dari negerinegeri yang dimusnahkan. Terdapat lima negeri: Shanàh, Sha'wah, Àtsrah, Dumah dan Sadum. Sedum merupakan negeri yang terbesar". ${ }^{28}$

b. Kajian dalam tema lafal ألصَََّْْة.

Dalam al-Qur'an, Allah swt. timpakan jenis azab ini kepada kaum Tsamud yang tidak mentaati perintah nabi Shalih. Bukti-bukti kebenaran telah sampai kepada mereka; seperti mukjizat yang nampak secara langsung agar mereka dapat mencerna bahwa yang dibawa nabi Shalih adalah sebuah kebenaran ilahi. Namun kesombongan mereka lebih besar sehingga menutup hidayah kebaikan. Dalam Tafsî́r Al-Qurân Al'Adzîm, Ibnu Katsir mengatakan;

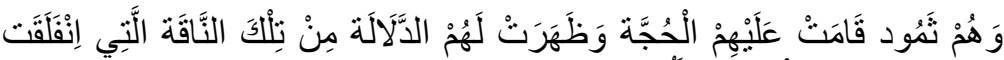

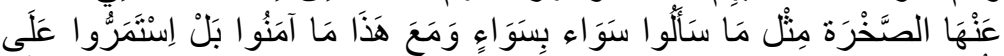

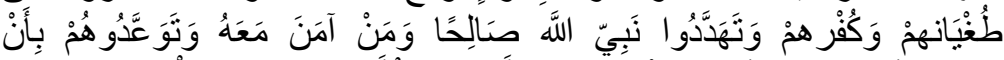

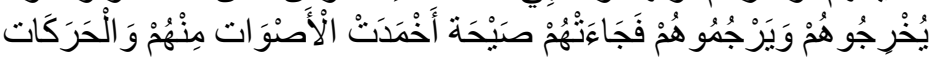

"Mereka adalah Tsamud yang telah sampai kepada mereka hujjah dan nampak bukti-bukti dengan keluarnya seekor unta dari sebuah batu seperti yang mereka minta, hukumannya sesuai dengan sikap

${ }^{27}$ As-Sa'di, "Taisîr Al-Karîm Ar-Rahmân", hlm. 445.

${ }^{28}$ Ibn Jarir Ath-Thabari, "Tafsîr Ath-Thabarî", hlm. 405. 
mereka. Di samping itu mereka tidak juga beriman, bahkan selalu berada pada kedurhakaan dan kekufuran. Mereka mengintimidasi nabi Allah Shalih dan orang-orang yang beriman bersamanya, dan mengancam akan mengusir dan merajam mereka. Maka datang suara keras yang dapat menghentikan suara dan gerakan mereka". ${ }^{29}$

Lafal صَنَحَة pada ayat ini terkorelasikan dengan beberapa lafal pada ayat al-Qur'an, yaitu;

1. الرَّ جْفَفَ pada surat al-A'raf: 78.

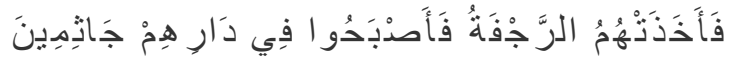

"Lalu datanglah kepada mereka gempa, dan merekapun mati bergelimpangan di dalam reruntuhan rumah mereka". [QS. Al A'raf: 78].

Ath-Thabari menuturkan;

$$
\begin{aligned}
& \text { حدثني محمد بن عمرو قال، حدثنا أبو عاصم قال، حدثنا عيسى، عن ابن أبي } \\
& \text { نجيح، عن مجاهد، في قول الله:"الرجفة" ، قال: الصيحة. }
\end{aligned}
$$

"Telah berbicara kepadaku Muhammad bin Amr, beliau berkata: telah berbicara kepadaku Abu Ashim, beliau berkata: telah berbicara kepadaku Isa dari Ibnu Abi Najih dari Mujahid tentang tafsir lafal الرجفة adalah 30

2. صلاعِقَِ pada surah Fusilat: 13.

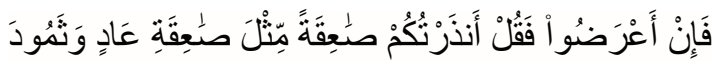

"Jika mereka berpaling maka katakanlah, "Aku telah memperingatkan kamu akan bencana petir seperti petir yang menimpa kaum "Àd dan kaum Tsamud”.

Al-Baghawi mengatakan;

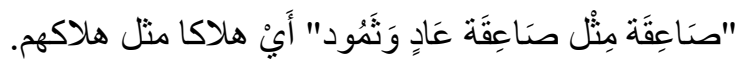

"Petir seperti petir yang menimpa kaum 'Ad dan Tsamud\}, yaitu bencana seperti bencana mereka". ${ }^{31}$

${ }^{29}$ Ibn Katsir, "Tafsîr Al-Qur'ân Al-`Adzîm", hlm. 120.

${ }^{30}$ Ibn Jarir Ath-Thabari, "Tafsîr Ath-Thabarî", hlm. 302.

${ }^{31}$ Al-Husain bin Masúd Al-Baghawiy, "Tafsîr Al-Baghawî̀", Jilid. VII (Riyad: Dar Thayyibah, 1412), hlm. 166. 
Terdapat korelasi antara lafaz Shaihah dan shâiqah pada penafsiran al-Baghawi, yaitu pada obyek azab yang telah Allah swt. timpakan kepada kaum Tsamud. Maka "kaum Tsamud" menjadi kata kunci untuk menyandingkan penjelasan ini dengan penjelasan mengenai lafaz Shaihah.

3. ألطَّاغِغَيَهِ pada surah al-Haqqah: 5.

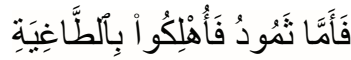

"Maka adapun kaum Tsamud mereka telah dibinasakan dengan suara yang sangat keras".

Dalam menjelaskan lafal tersebut, As Sa'di mengatakan;

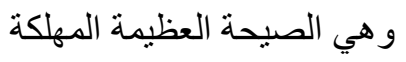

"Yaitu suara besar yang membinasakan". 32

Dari beberapa penjelasan terkait lafal ألصََيْحَةُ maka penggabungan maknanya adalah bencana berupa petir yang keras, dan mengakibatkan gempa yang mampu menghancurkan rumah-rumah serta mematikan manusia.

c. Kajian dalam tema kalimat خَسَفْنا بِهِ آَلْنَزْضَ.

Terdapat riwayat dalam tafsir ath-Thabari dari al-Qasim, beliau mengatakan;

حدثنا الحسين، قال: ثني حجاج، عن ابن جُرَيج، قال: قال ابن عباس: (وَرِنْهُمْ

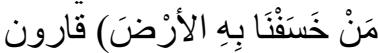

"Telah berkata kepada kami al-Husain, beliau berkata: telah berkata kepada kami Hajaj dari Ibnu Juraij berkata: telah berkata Ibnu Abbas (dan dari mereka ada yang ditenggelamkan ke dalam bumi) yaitu Qarun". 33

Dalam surah al-Qashash Allah swt. ceritakan perihalnya, Allah swt. berfirman;

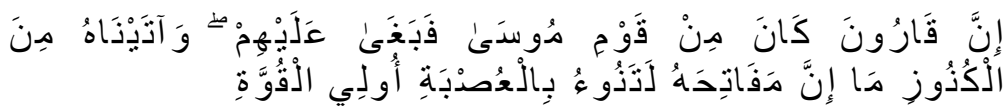

"Sesungguhnya Qarun termasuk kaum nabi Musa, maka ia berlaku aniaya terhadap mereka, dan Kami telah menganugerahkan

${ }^{32}$ As-Sa'di, "Taisîr Al-Karîm Ar-Rahmân", hlm. 1041.

${ }^{33}$ Ibn Jarir Ath-Thabari, "Tafsîr Ath-Thabarî", hlm. 402. 
kepadanya perbendaharaan harta yang kunci-kuncinya sungguh berat dipikul oleh sejumlah orang yang kuat-kuat".

Allah swt. mengabarkan keadaan Qarun yang zalim dan melampaui batas serta bermaksiat kepada Rabbnya. Dengan bersikap sombong dan takjub kepada dirinya sendiri. Maka Allah swt. tenggelamkan dia beserta hartanya ke dalam bumi. Itulah balasan yang sesuai dengan perbuatannya, karena harta yang banyak pada umumnya disimpan di bawah tanah. ${ }^{34}$

d. Kajian dalam tema lafal أَغْرَفْنَا.

Ungkapan أغرَق dalam al-Qur'an terdapat pada pembicaraan tentang azab di dunia untuk umat-umat terdahulu sebagai sarana Allah swt. ketika membinasakan mereka. Maka ungkapan tersebut telah mengambil makna dari sebuah bukti kehancuran dan kematian, karena keterkaitannya dengan azab dunia di dalam al-Qur'an. Bahkan kalimat ini jika disebutkan maka secara langsung fikiran tertuju kepada kecelakaan dan kematian. ${ }^{35}$

Terdapat dua contoh dalam al-Qur'an peristiwa azab penenggelaman yang Allah swt. berikan kepada hambanya, yaitu kepada kaum nabi Nuh dan Firáun. ${ }^{36}$ Kedua contoh tersebut memiliki kesamaan pada akhir kisah, namun alur peristiwanya yang berbeda. Lafal غرَق yang membicarakan kaum nabi Nuh dan Firáun terdapat di beberapa ayat dalam surah-surah al-Qur'an. Ayat -ayat yang berbicara tentang kaum nabi Nuh diantaranya adalah: QS. Al-A'raf: 64, QS. Yunus: 73, QS. Hud: 37 dan 43, QS. Al-Anbiya': 77, QS. Al-Mukminun: 27, QS. Al-Furqan: 37, QS. Asy-Syuara': 120, QS. Yasin: 43, QS. ash-Shafat: 8, QS. Nuh: 25. Dan yang berbicara tentang Firáun diantaranya adalah: QS. Al-Baqarah: 50, QS. Al-A'raf: 136, QS. Al-Anfal: 54, QS. Yunus: 90, QS. Al-Isra': 103.

Pada peristiwa kaum nabi Nuh, lafal غرَق merupakan dampak dari banjir yang telah Allah swt. datangkan akibat

${ }^{34}$ Amin Asy-Syafií, "Tafsîr Hadâiq Ar-Rûh wa Ar-Rahmân", hlm. 415.

${ }^{35}$ Hamadah Muhammad Abdul Fattah Al-Husaini, "Alfâdz Adawât AlAdzâb fî Ad-Dunyâ" (Kairo, 2003), hlm. 272-273.

${ }^{36}$ Al-Hishn Al-Manshuri, "Al-Muqtathaf min Ùyûn At-Tafâsîr", hlm. 176. 
pembangkangan untuk mengikuti rasul Allah dan bentuk kesyirikan yang merajalela. Telah terilustrasikan kejadian itu dalam surah al-Qamar ayat 11 dan 12, Allah swt. berfirman;

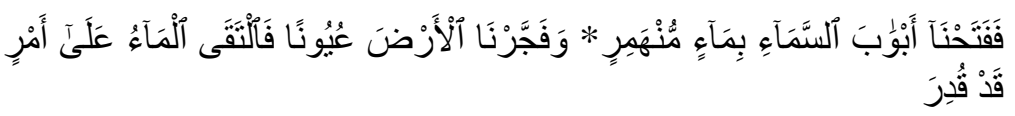

"Maka Kami bukakan pintu-pintu langit dengan air yang mencurah.

Dan kami jadikan bumi memancarkan mata air-mata air, maka menyatulah air-air itu dengan urusan yang telah ditentukan".

Ibnu Katsir mengomentari ayat di atas;

$$
\begin{aligned}
& \text { قال ابن جريج عن ابن عباس }
\end{aligned}
$$

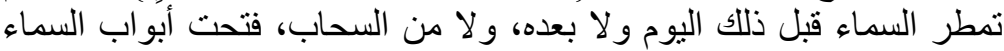

$$
\begin{aligned}
& \text { بالماء من غير سحاب ذللك اليوم، فالتقى الماءوان لان على أمر قد قدر }
\end{aligned}
$$

"Telah berkata Ibnu Juraij dari Ibnu Abbas (dan telah kami bukan pintu-pintu langit dengan menurunkan air yang mencurah) yaitu banyak. Langit tidak pernah menurunkan hujan sebelum dan sesudah itu, dan tidak pula hujan yang turun dari awan. Maka pada hari itu dibuka pintu-pintu langit dengan menurunkan air yang bukan dari awan, bertemulah dua air atas perkara yang telah ditentukan". ${ }^{37}$

Lafal غرَق pada kisah Firaun adalah reaksi dari keberanian Firaun untuk membunuh nabi Musa dan pengikutnya dalam belahan lautan. Ketika mereka mengejar nabi Musa dan pengikutnya kemudian mereka dapati nabi Musa dan pengikutnya telah sampai di seberang lautan karena mukjizat dari Allah swt., Firáun berfikir akan seperti nabi Musa dan pengikutnya. Namun ketika mereka mengejar dan sampai dipertengahan Allah swt. tutup kembali lautan itu dan menenggelamkan Firaun dan tentaranya. Dalam surah Thaha ayat 78 Allah swt. berfirman;

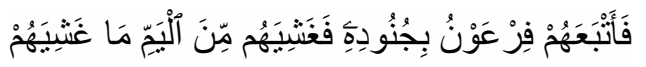

"Maka Firaun dan bala tentaranya mengejar mereka (Musa dan pengikutnya), lalu mereka ditutup oleh laut yang menenggelamkan mereka".

${ }^{37}$ Ibn Katsir, "Tafsîr Al-Qur'ân Al-`Adzîm", hlm. 309. 
Dalam QS al-Ankabut: 40 terdapat empat desain cara Allah swt. untuk menghancurkan orang-orang yang mendustakan Allah swt. dan rasul-Nya. Yaitu api yang disertakan dengan batu kerikil, angin yang berhembus bersama suara yang keras, tanah dan air yang meneggelamkan. ${ }^{38}$ Keempat unsur tersebut sangat dibutuhkan tubuh manusia dalam kehidupan di dunia, dengannya seorang akan bisa tumbuh dan bertahan. Namun jika Allah swt. menghendaki azab kepada manusia, apapun yang ada bisa menjadi perantara terwujudnya keinginan tersebut, walaupun unsur yang sebenarnya bermanfaat bagi manusia bisa menjadi sesuatu yang berbahaya.

Ketika Allah swt. seru mereka agar mengikuti rasul-Nya sebagai agen pembawa kehidupan rohani, mereka enggan dan lebih memilih kehidupan dunia. Sehingga bentuk penolakan mereka terhadap unsur-unsur yang mampu menghidupkan rohani mereka; Allah swt. ganti dengan azab yang hakikatnya memberikan manfaat pada kehidupan dunia mereka, sebagai hukuman dari sebuah pilihan salah yang dianggap sebagai kebenaran.

\section{E. Kesimpulan}

Dari uraian di atas, dapat di simpulkan bahwa Allah dalam memberikan azab kepada hambanya tidak hanya pada satu jenis, melainkan terdapat bentuk dan macamnya. Sehingga fungsi dari varietasi azab adalah menyesuaikan kemaksiatan dan keadaan yang ada pada saat diturunkannya azab tersebut.

Dalam surah al-Ankabut ayat 40 terdapat empat jenis azab yang Allah swt. turunkan kepada manusia sebagai balasan langsung di dunia, yaitu hujan batu kerikil, suara petir yang menggelegar, ditenggelamkan di laut dan dibenamkan ke dalam tanah. Kesamaan dari keempat azab ini terletak pada latar belakang dan akhirnya, yaitu yang didahului dengan pembangkangan kepada Allah swt. dan mendustakan rasul yang diutus kepada mereka sebagai salah satu bentuk kekufuran kemudian kematian karena azab sebagai akhir kisahnya.

${ }^{38}$ Fakhruddin Ar-Razi, "Mafâtîh Al-Ghaib", Jilid. XXV (Lebanon: Dar Al-Fikr, 1981), hlm. 68. 
Pada intinya, azab dalam surah al-Ankabut ayat 40 adalah menjelaskan beragam bentuk azab secara global belum secara spesifik. Mengenai bentuk azab yang lebih spesifik bisa mencari di ayat-ayat al-Qur'an yang lain sambil menggunakan teori munasabah. Jadi, kesimpulannya pada tulisan ini ialah hanya menjelaskan beberapa bentuk dan azab yang ada di al-Qur'an, khususnya pada surah al-Ankabut ayat 40. Sejatinya, azab Allah swt. juga masih banyak. Di samping itu, pencarian bentuk azab melalui redaksi variasi kata digali dari beberapa ayat al-Qur'an dan para ahli tafsir.

\section{DAFTAR PUSTAKA}

Abdul Fattah Al-Husaini, Hamadah Muhammad. "Alfâdz Adawât Al-Adzâb fî̀ Ad-Dunyâ". Kairo, 2003.

Abdul Jalil Yusuf, Husna. "Tashîl Syarh Ibn Àqîl". Kairo: Yayasan Al-Mukhtar, 2000.

Abdullah bin Aqil, Bahauddin. "Syarh Ibn Àqûl". Jilid. II. Kairo: Dar Ath-Thalaì, 2004.

Adz-Dzahabi, Muhammad Husain. "İlmu At-Tafsîr". Kairo: Dar Al-Maárif, t.t.

Al-Baghawiy, Al-Husain bin Masúd. "Tafsîr Al-Baghawî". Jilid. VII. Riyad: Dar Thayyibah, 1412.

Al-Baghdadi, Jamaluddin. "Zâd Al-Masîr fî Ilmi At-Tafsîr". Jilid. VI. Beirut: Al-Maktabah Al-Islamiyyah, 1984.

Al-Hishn Al-Manshuri, Musthafa. "Al-Muqtathaf min Ùyûn AtTafâsîr". Jilid. VI. Beirut: Ad-Dar Asy-Syamiyyah, t.t. Al-Qaththan, Manna' Khalil. "Mâbahits fì Ùlûm Al-Qur'an". Kairo: Maktabah Wahbah, t.t. 
Al-Qurthubi, Muhammad bin Ahmad bin Abu Bakar. "Al-Jâmi" Liahkâm Al-Qur'ân". Jilid. XXI. Lebanon: Yayasan ArRisalah, 2006.

Amin Asy-Syafií, Muhammad. "Tafsîr Hadâiq Ar-Rûh wa ArRahmân". Jilid. XXI. Lebanon: Dar Thuq An-Najah, 2001.

Aqilah Al-Makki, Ibnu. "Az-Ziyâdah wa Al-Ihsân fì Ùlûm AlQur'ân". Jilid. VI. UEA: Markaz Al-Buhuts wa AdDirasah, 2006.

Ar-Razi, Fakhruddin. "Mafâtîh Al-Ghaib". Jilid. XXV. Lebanon: Dar Al-Fikr, 1981.

As-Sa'di, Abdurrahman. "Taisîr Al-Karîm Ar-Rahmân". KSA: AlBayan, t.t.

Athiyyah Al Andalusi, Ibnu. "Al-Muharrar Al-Wajîz fì Tafsîr AlKitâb Al-Azîzz". Jilid. IV. Lebanon: Dar Al-Kutub AlIlmiyyah, 2001.

Audhullah Abbas, Abbas. "Muhâdharât fî At-Tafsîr Al-Maudhû̂̀". Damaskus: Dar Al-Fikr, 2007.

Az-Zarqani, Muhammad Abdul Adzim. "Manâhil Al-İrfân fì Ùlûm Al-Qur'ân". Jilid. 1. Lebanon: Dar Al-Kutub Al-Arabi, 1995.

Ibn Jarir Ath-Thabari, Muhammad. "Tafsîr Ath-Thabarî". Jilid. XVIII. Kairo: Markaz Al-Buhuts wa Ad-Dirasat AlArabiyyah wa Al-Islamiyyah, 2001.

Ibn Katsir, Ismail. "Tafsîr Al-Qur'ân Al-`Adzîm". Jilid. VIII. Kairo: Al Maktabah At Tufiqiyyah, 2012.

Ibnu Asyur, Muhammad Ath Thahir. "Tafsîr At-Tahrîr wa AtTanwîr". Jilid. XX. Tunisia: Ad-Dar At-Tunisiyyah, 1984.

Ismail An-Nahas, Ahmad bin Muhammad bin. "I'râb Al-Qurân". Jilid. III. Maktabah Nahdzah Al-Arabiyyah, 1985.

Muslim, Musthafa. "Mabâhits fì At-Tafsîr Al-Maudhû̂̀". Riyad: Dar At-Tadmuriyyah, 2009.

Musthafa Al-Hanafi, Ismail. "Tafsîr Rûh Al-Bayân". Jilid. VI. Dar Ihya' At-Turats Al-Arabi, t.t.

Salim Muhaisin, Muhammad. "Târîkh Al-Qur'ân Al-Karîm". Jeddah: Dar Al-Ashfahan, 1402. 
Yoga Riyandi

Ulama' Pilhan, Sekumpulan. "At-Tafsîr Al-Muyassar". Mesir: Dar Al-Islam, 2012.

Ulama' Tafsir, Sekumpulan. “Al-Mukhtashar fì Tafsîr Al-Qur'ân Al-Karîm". Riyad: Markaz Tafsir liddirasat At Tafsiriyyah, 1439. 